\title{
HEAD AND NECK
}

\section{Sclerotherapy with polidocanol microfoam in head and neck venous and lymphatic malformations}

\author{
La scleroterapia con polidocanolo nella gestione delle malformazioni venose \\ e linfatiche del distretto testa-collo
}

\author{
Eugenio De Corso', Alessandro Cina², Giampiero Salonna, Giovanni Di Cintio¹, Simona Gaudino², Marco Panfili², \\ Cesare Colosimo², Gaetano Paludetti ${ }^{1}$ \\ UOC Otorinolaringoiatria, Area Testa-Collo, Fondazione Policlinico Universitario A. Gemelli IRCCS, Università Cattolica del Sacro \\ Cuore, Rome, Italy; ${ }^{2}$ UOC Radiodiagnostica e Neuroradiologia, Dipartimento di Diagnostica per Immagini, Radioterapia, Oncologia \\ ed Ematologia, Fondazione Policlinico Universitario A. Gemelli IRCCS, Rome, Italy
}

\begin{abstract}
SUMMARY
Objective. Polidocanol sclerotherapy of head and neck venous malformations (VMs) and lymphatic malformations (LMs) has been reported only in limited series. In this manuscript we evaluated the efficacy and safety of polidocanol sclerotherapy in a series of head and neck venous and lymphatic malformations.

Methods. This retrospective observational study analysed data on 20 head and neck VMs and LMs that underwent to percutaneous or endoscopic intra-lesional $3 \%$ polidocanol microfoam sclerotherapy at our institution. Clinical response was ranked as excellent, moderate and poor based on volume reduction by MRI and resolution of symptoms.

Results. The median volume decreased from $19.3 \mathrm{~mL}$ to $5.8 \mathrm{~mL}$ after sclerotherapy (mean volume reduction: $72.98 \pm 16.1 \%$ ). An excellent-moderate response was observed in $94.4 \%$ of cases. We observed a mean volume reduction of $79.5 \pm 16.1$ in macrocystic LMs, of $76.1 \pm 13.0 \%$ in VMs, of $60.5 \pm 10.9 \%$ in mixed lymphatic ones and $42.5 \%$ in microcystic lymphatic ones.

Conclusions. Polidocanol sclerotherapy appears to be an effective and safe treatment for venous and lymphatic head and neck malformations. We observed the best responses in macrocystic LMs and VMs, whereas mixed lymphatic ones showed a moderate response and microcystic lymphatic ones a poor response.
\end{abstract}

KEY WORDS: lymphatic malformations, venous malformations, sclerotherapy, polidocanol, vascular malformations

\section{RIASSUNTO}

Obiettivi. La scleroterapia con polidocanolo (POL) nelle malformazioni venose (VM) e nelle malformazioni linfatiche (LM) della testa e del collo è stata descritta solo in casisitiche limitate. In questo lavoro abbiamo valutato l'efficacia e la sicurezza del POL in pazienti affetti da VM e LM della testa e del collo.

Metodi. Sono stati analizzati i dati di 20 pazienti affetti da VM e LM del testa-collo, sottoposti a scleroterapia con POL al 3\%, iniettato nella lesione per via percutanea o endoscopica. La risposta è stata classificata come eccellente, moderata o scarsa in base alla riduzione del volume valutata mediante risonanza magnetica e alla risoluzione dei sintomi. Risultati. Il volume mediano si è ridotto da 19,3 $\mathrm{ml}$ a 5,8 $\mathrm{ml}$ dopo il trattamento (riduzione volumetrica media: $72,98 \pm 16,1 \%$ ). Il 94,4\% dei casi ha ottenuto una riposta eccellente-moderata. In particolare è stata osservata una riduzione volumetrica media del $79,5 \pm 16,1 \%$ nelle LM macrocistiche, del 76,1 $\pm 13,0 \%$ nelle VM, del 60,5 $\pm 10,9 \%$ LM miste e del 42,5\% nell'unica LM microcistica.

Conclusioni. La scleroterapia con POL sembra essere un trattamento efficace e sicuro: $i$ risultati migliori sono stati ottenuti nelle LM macrocistiche e nelle VM, mentre le LM miste hanno mostrato una moderata risposta e le LM microcistiche una scarsa risposta.

PAROLE CHIAVE: malformazioni linfatiche, malformazioni venose, scleroterapia, polidocanolo, malformazioni vascolari
Received: December 14, 2020

Accepted: February 20, 2021

Published online: July 23, 2021

\section{Correspondence}

Giovanni Di Cintio

UOC Otorinolaringoiatria, Area Testa-Collo. Fondazione Policlinico Universitario A. Gemelli IRCCS, Università Cattolica del Sacro Cuore, largo A. Gemelli 8, 00168 Rome, Italy

Tel. +3906 30154439

E-mail: dicintiogiovanni@gmail.com

\begin{abstract}
How to cite this article: De Corso E, Cina A, Salonna G, et al. Sclerotherapy with polidocanol microfoam in head and neck venous and lymphatic malformations. Acta Otorhinolaryngol Ital 2022;42:116-125. https://doi. org/10.14639/0392-100X-N1310
\end{abstract}

(C) Società Italiana di Otorinolaringoiatria e Chirurgia Cervico-Facciale

\section{(c) $(1)$}

This is an open access article distributed in accordance with the CC-BY-NC-ND (Creative Commons Attribution-NonCommercial-NoDerivatives 4.0 International) license. The article can be used by giving appropriate credit and mentioning the license, but only for non-commercial purposes and only in the original version. For further information: https:// creativecommons.org/licenses/by-nc-nd/4.0/deed.en 


\section{Introduction}

Venous and lymphatic malformations are heterogeneous group of pathologies characterised by morpho-structural and/or functional alterations that can affect any type of blood and/or lymphatic vessel of any calibre or anatomical district ${ }^{1}$. The classification of International Society for the Study of Vascular Anomalies (ISSVA) ${ }^{2}$ is commonly used and subdivides vascular anomalies into two main groups: vascular tumours and vascular malformations ${ }^{3}$. The latter group encloses high-flow lesions (arteriovenous malformations and arteriovenous fistula) and low-flow ones, including venous and lymphatic malformations.

Venous malformations (VMs) account for 44-64\% of all vascular malformations, with an incidence in the general population between $0.8 \%-1 \%{ }^{4}$. About $40 \%$ of VMs affect head and neck region ${ }^{5}$. Lymphatic malformations (LMs) result from embryogenetic defects of lymphangiogenesis and $75 \%$ of cases are localised in the head and neck region and may result in functional and aesthetic deficits that may have a negative psychosocial impact, particularly if untreated ${ }^{6}$.

The optimal paradigm for management of venous and lymphatic malformations has yet to be established. Management strategies include "wait and see" with medical treatment of exacerbations, sclerotherapy, or surgical resection. From a clinical point of view, it is very useful to distinguish between high-flow and low-flow vascular malformations in order to determine the most appropriate treatment strategy. In fact, percutaneous sclerotherapy, which is not generally indicated for high-flow lesions, has become a popular alternative to surgical treatment for low-flow vascular malformations ${ }^{7}$. De Maria et al. recently confirmed in a meta-analysis that percutaneous sclerotherapy is a very safe and effective modality for treatment of VMs of the head, neck and face ${ }^{8}$.

To date, several different agents have been proposed for sclerotherapy with variable rates of efficacy. Ethanol, although one the first sclerosing agents used for vascular malformations, is rarely chosen today due to its substantial side effects, such as skin complications (necrosis, pain and blistering), peripheral nerve injury, respiratory depression, cardiac arrhythmia, seizure, rhabdomyolysis and hypoglycaemia ${ }^{9}$. In a review in 2016, Horbach et al. reported that the rate of complications was higher after ethanol sclerotherapy (18\%) compared to other sclerosing agents $(0-6 \%)^{7}$.

As an alternative OK-432 (lyophilised mixture of Streptococcus pyogenes and benzylpenicillin) has been used to treat successfully mainly macrocystic lymphatic malformations ${ }^{10}$. Bleomycin, initially developed as an anti-tumour agent, has been used in the treatment of both microcystic and macrocystic LMs ${ }^{11}$. Finally, doxycycline, a broadspectrum antibiotic, has been demonstrated to be safe and effective in managing head and neck macrocystic and mixed LMs ${ }^{12}$.

Polidocanol (hydroxy-polyethoxy-dodecane - POL), a synthetic long-chain fatty alcohol, is a liquid surfactant with endothelial cytolytic properties and has mainly been used for venous malformations. Polidocanol injection is painless, does not induce necrosis if injected intradermally and rarely produces allergic or inflammatory reactions ${ }^{13-17}$. Recently, it has also been proposed for lymphatic ones even though it has been investigated in only a limited number of studies based on small samples, including several sites and not focused only on head and neck cases ${ }^{14,17,18}$.

Herein, we report our protocol for head and neck lesions describing our endoscopic and percutaneous approaches that are performed in close cooperation between an interventional radiologist and ENT surgeon. Specifically, the objective of this study was to analyse the efficacy and safety of polidocanol sclerotherapy for head and neck vascular malformations in term of volume reduction at MRI and resolution of symptoms at clinical evaluation.

\section{Materials and methods}

\section{Study population and study design}

This is a non-profit retrospective observational study performed at a single institution. Inclusion criteria were: patients treated by sclerotherapy at our institution because of symptoms (dysphagia, dyspnoea, pain), aesthetic concerns with a negative psychosocial impact, oncoming risk of airway obstruction, increasing volume at radiological followup. Exclusion criteria were: high flow vascular malformations, previous surgery or previous sclerotherapy for the lesion to treat. Based on inclusion and exclusion criteria, we analysed data on 23 consecutive patients with head and neck vascular malformations who were diagnosed, treated and followed at our institution between January 2016 and November 2019. Three patients were excluded: one oral arteriovenous malformation treated with angiographic embolisation; two life-threatening mixed giant lymphatic congenital malformations requiring surgery (the first treated with surgery and sirolimus; the second with sclerotherapy with OK-432-Picibanil, surgery and medical therapy with sirolimus).

LMs were categorised based on cyst dimension as follows: macrocystic $(\mathrm{M}>50 \%$ of cysts larger than $2 \mathrm{~cm})$, mixed (mix, $<50 \%$ of cysts larger than $2 \mathrm{~cm}$ ) and microcystic (m, all cysts smaller than $2 \mathrm{~cm})^{19}$. They were classified according to the de Serres staging system ${ }^{20}$ : stage I (unilateral infrahyoid disease), stage II (unilateral suprahyoid disease), stage III (unilateral infrahyoid and suprahyoid 
disease), stage IV (bilateral infrahyoid disease) and stage $\mathrm{V}$ (bilateral infrahyoid and suprahyoid disease).

The data were directly obtained from our computerised clinical database and medical records. Informed consent about privacy and utilisation of clinical data was obtained from patients at the time of original data collection. The data were anonymously analysed. The following data were taken into consideration: symptoms, site of malformations, clinical objective characteristics of the lesions at ENT physical evaluation, videolaryngoscopy, pre-treatment magnetic resonance imaging (MRI) features, treatment modalities and complications. Finally, we analysed outcomes at 6-months in terms of resolution of symptoms and reduction of radiological volume at MRI.

\section{Clinical management}

In our clinical practice, candidates for sclerotherapy usually undergo pre-operative clinical examination, endoscopy of the upper airways and MRI. We usually discuss each case with an expert head and neck radiologist to confirm the diagnosis, characterising the type, site and extension of the lesion before treatment. All this information is particularly important for adequate counselling and treatment planning. We usually suggest sclerotherapy in case of symptoms (dysphagia, dyspnoea, pain), aesthetic concerns with a negative psychosocial impact and poor quality of life, oncoming risk of airway obstruction and increasing volume at radiological follow-up. Sclerotherapy is generally performed on outpatients unless involvement of the upper airways requires general anaesthesia and overnight observation. Antibiotics are administered during treatment and paracetamol is given after treatment if required for pain; soft and cold diet plus $0.12 \%$ chlorhexidine gluconate mouthwash for 5 days are prescribed in case of upper airway lesions. The first clinical follow-up with ultrasound and endoscopy was usually performed at 4 weeks after the procedure in all patients. In case of moderate volume reduction and/or persistence of symptoms, patients are recommended for a second injection that is usually performed 6-8 weeks after the first one. Finally, patients undergo physical and MRI radiological examination at 6 months following the last injection.

\section{Sclerotherapy technique}

The sclerosing solution used in this study was 3\% POL microfoam (Polidocasklerol; Zeria Pharmaceutical Co, Ltd, Tokyo, Japan). The sclerosing foam was provided on-site by direct injection using a liquid to air ratio of 1:4. Two syringes were attached by a three-way stopcock, one filled with POL and the other with air; the foam was obtained by mixing the two syringes with multiple passages as described by Tessari ${ }^{21}$.
Vascular malformations of upper aero-digestive airways were treated by endoscopic-guided trans-oral direct injection. Previous sedation or general anaesthesia, a 20-gauge venous catheter (JELCO PLUS; Smiths Medical Japan Ltd, Tokyo, Japan) was inserted into the lesion for no more than $1 \mathrm{~cm}$ (to make sure the right depth has been reached, plastic cover wrapping the distal portion of $1 \mathrm{~cm}$ from the extremity of the catheter was removed). The needle was placed into the lesion at the point of maximal deformation and then $3 \%$ POL-microfoam was injected after aspiration of part of the liquid contained within the lesion.

Cervical lesions (without involvement of aero-digestive airways) were treated by percutaneous procedures under local anaesthesia with ultrasound guidance. In these cases, $3 \%$ POL-microfoam was directly injected under ultrasound guidance with a 20 -gauge needle with previous aspiration of an adequate amount of liquid contained within the lesion. We performed all procedures in close collaboration with an interventional radiologist in order to share expertise and improve the precision during both ultrasound-guided and endoscopic-guided injection.

In case of macrocytic lesions a single injection is performed, while in other cases additional injections may be required. The volume injected depended on the size of the malformation and on the amount of aspirated content of the lesion. However, the maximum dose of injected sclerosant did not exceed $2 \mathrm{mg} / \mathrm{kg}$ of POL independently of the number of injections. The common pharmaceutical form of POL is a 2-mL 3\% ampule for injection and contains 60 $\mathrm{mg}$ of POL. Hence, the maximum volume of POL liquid is $0.067 \mathrm{~mL} / \mathrm{kg}$. This means that the maximum volume of foam that can be provided from 3\% POL by the Tessari method using a liquid to air ratio of $1: 4$ is $0.34 \mathrm{~mL} / \mathrm{kg}$.

\section{Outcomes}

Volumetric analysis was carried out by an expert head and neck radiologist using a workstation (Advanced Workstation $4.7^{\circledR}$, GE Healthcare) with dedicated software (Volume Viewer $^{\circledR}$, GE Healthcare), evaluating pre- and post-procedural MRI studies. Lesion volume was calculated using semiautomatic segmentation with the summation-of-area technique. The lesion was manually segmented on all axial T2-weighted images and the software automatically reconstructed and calculated the volume ${ }^{22,23}$.

The efficacy of the procedure was evaluated in terms of resolution of clinical symptoms and volume reduction by MRI comparing preoperative MRI lesion volume with that at 6 months. An excellent response was assumed if $>90 \%$ volume reduction and complete resolution of symptoms was observed; a moderate response was considered in case of $50-90 \%$ volume reduction and partial or complete 
resolution of symptoms; poor response was noted in case of $<50 \%$ volume reduction and partial or no resolution of symptoms. In our experience, the polidocanol was completely resorbed at the post treatment MRI at 6 months.

Our experience with polidocanol sclerotherapy began in 2016, and thus the maximum length of follow-up is 4 years, with a mean long-term follow-up of 34 months. We usually perform clinical ENT evaluation and ultrasound monitoring every year.

We also evaluated the safety, side effects, average length of stay and need for supportive medical treatment.

\section{Statistical analysis}

Clinical and demographic characteristics were described with descriptive statistics. In particular, the quantitative variables were represented by minimum, maximum, median, range, average and standard deviation (SD), and qualitative ones by absolute and percentage frequencies.

SPSS program version 25.0 (SPSS Inc; IL, USA) was used for statistical analysis. Continuous values such as volume of the lesions, were expressed as median and range. Volume reduction was express as mean $\pm \mathrm{SD}$. Baseline and posttreatment values were compared using Student's test for paired samples in normally distributed values and MannWhitney U-test for non-normally distributed data. Results were considered significant for $\mathrm{p}<0.05$.

\section{Results}

Twenty patients were included in the analysis [ 8 females (40\%); mean age $26.3 \pm 14.4$ years (range 7-60)] who underwent direct intra-lesional sclerotherapy with $3 \%$ POL microfoam; 7/20 (35\%) were paediatric patients $\leq 18$ years and $13 / 20(65 \%)$ were adults. None had previously received surgical treatment or sclerotherapy with sclerosant agents. The lesions were classified based on the ISSVA classification as follow: 13/20 (65\%) LMs and 7/20 (35\%) VMs. LMs were macrocystic in $7 / 13(53.8 \%)$, mixed in 5/13 (38.5\%) and microcystic in $1 / 13(7.7 \%)$. According to the de Serres staging system, 3/13 (23.1\%) were stage I, 6/13 (46.1\%) stage II, $3 / 13(23.1 \%)$ stage III and $1 / 13(7.7 \%)$ stage V.

Baseline characteristics of patients and anatomic localisation of the head and neck lesions are reported in Table I. Clinical characteristics for each patient are summarised in Table II. We treated 12 patients by a percutaneous procedure under ultrasound guidance and 8 patients by direct endoscopic injection as reported in Table III.

We observed a significant difference between pre-treatment mean MRI diameters [46.8 × $32.8 \times 28.8 \mathrm{~mm}$; craniocaudal (CC), antero-posterior (AP), laterolateral (LL), respectively] versus post-treatment ones $(31.3 \times 21.5 \mathrm{x}$
Table I. Cases series: demographics, vascular malformations and anatomic distribution.

\begin{tabular}{lc} 
Case series & $\mathbf{N}=\mathbf{2 0}$ \\
Demographics & \\
Age & $26.85 \pm 14.4 \mathrm{DS}$ \\
& $($ range $7-60)$ \\
Female & $8 / 20(40 \%)$ \\
Male & $12 / 20(60 \%)$ \\
Vascular malformations & \\
Venous malformations & $7 / 20(35 \%)$ \\
Lymphatic malformations (LMs) & $13 / 20(65 \%)$ \\
$\quad$ Macrocystic LMs & $7 / 13(53.8 \%)$ \\
$\quad$ Mixed LMs (Macrocystic and Microcystic) & $5 / 13(38.5 \%)$ \\
$\quad$ Microcystic LMs & $1 / 13(7.7 \%)$ \\
Anatomic distribution & \\
Lateral neck region & $4 / 20(20 \%)$ \\
Oropharynx & $3 / 20(15 \%)$ \\
Oral cavity & $4 / 20(20 \%)$ \\
Parotid - parapharyngeal space & $2 / 20(10 \%)$ \\
Parotid - masticatory space & $3 / 20(15 \%)$ \\
Submandibular-floor of the mouth & $3 / 20(15 \%)$ \\
Eyelid & $1 / 20(5 \%)$ \\
\hline
\end{tabular}

$17.5 \mathrm{~mm}$; CC, AP, LL, respectively) $(\mathrm{p}<0.05)$. The median pre-treatment volume evaluated by dedicated software was $20.58 \mathrm{~mL}$ (range $0.3 \mathrm{~mL}-436.8 \mathrm{~mL}$ ) and decreased to 6.1 $\mathrm{mL}$ post-sclerotherapy (range $0.05 \mathrm{~mL}-176 \mathrm{~mL})(\mathrm{p}<0.05)$. Finally, a mean volume reduction of $73.38 \%$ was observed considering all cases.

A subanalysis based on the type of lesion was performed. Preoperative median volume for VMs was $3.5 \mathrm{~mL}$ (range $0.3 \mathrm{~mL}-436.8 \mathrm{~mL}$ ) and reduced post-operatively to $0.3 \mathrm{~mL}$ (range $0.05 \mathrm{~mL}-176 \mathrm{~mL}$ ), with a mean volume reduction of $76.1 \%(\mathrm{p}<0.05)$. The median preoperative volume of LMs was $21.5 \mathrm{~mL}$ (range $0.96 \mathrm{~mL}-117 \mathrm{~mL}$ ) and decreased post-treatment to $6.5 \mathrm{~mL}$ (range $0.08 \mathrm{~mL}-16.9 \mathrm{~mL}$ ), with a mean volume reduction of $71.8 \%(\mathrm{p}<0.05)$. Considering the type of LM, we observed that the median volume reduction decreased from $19.6 \mathrm{~mL}$ (range $0.9 \mathrm{~mL}-117 \mathrm{~mL}$ ) to $5.1 \mathrm{~mL}$ (range $0.08 \mathrm{~mL}-11.3 \mathrm{~mL})(\mathrm{p}<0.05)$ in macrocystic LMs; from $21.5 \mathrm{~mL}$ (range $10.1 \mathrm{~mL}-21.5 \mathrm{~mL}$ ) to $6.5 \mathrm{~mL}$ (range $3.5 \mathrm{~mL}-10.5 \mathrm{~mL})(\mathrm{p}<0.05)$ in mixed LMs; from $29.3 \mathrm{~mL}$ to $16.9 \mathrm{~mL}$ in microcystic one. The volume reduction was $79.5 \%$ in macrocystic LMs, $67.1 \%$ in mixed LMs and $42.5 \%$ in the microcystic one.

In our series, the average amount of POL injected was 3.58 cc (3-10 cc) and general anaesthesia was required in $6 / 20$ (30\%) patients. The mean duration of hospitalisation was 1.15 days. Table III shows the effectiveness, safety and tech- 
Table II. Clinical characteristics of patients.

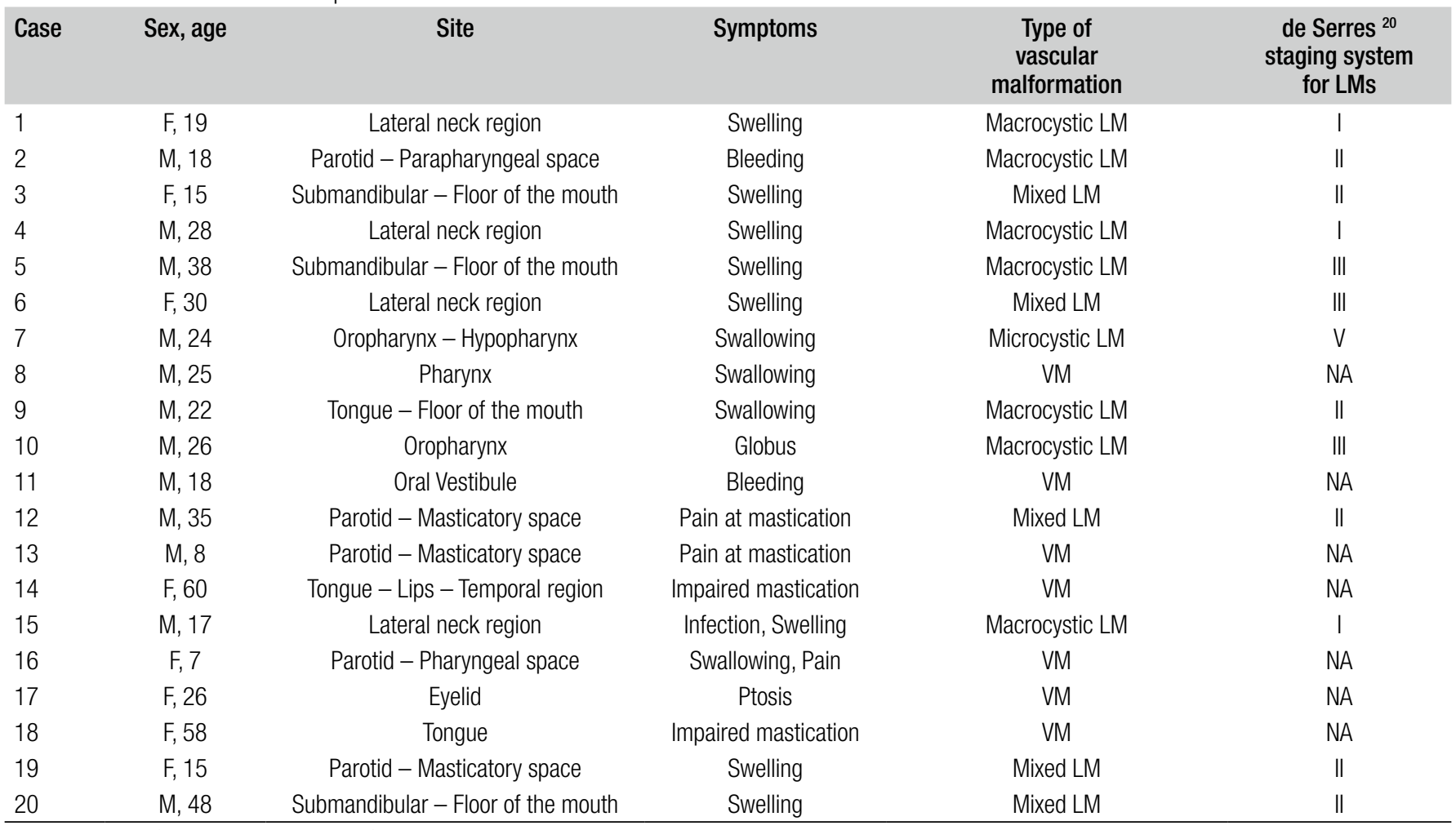

LM: Iymphatic malformation; VM: venous malformation; NA: not-applicable.

Table III. Technical details, safety and outcomes of the procedures.

\begin{tabular}{|c|c|c|c|c|c|c|c|c|c|}
\hline Case & $\begin{array}{c}\text { MRI pre } \\
\text { dimension } \\
\text { dCCxLLxAP }\end{array}$ & $\begin{array}{l}\text { MRI post } \\
\text { dimension } \\
\text { dCCXLLXAP }\end{array}$ & $\begin{array}{l}\% \text { volume } \\
\text { reduction }\end{array}$ & $\begin{array}{l}\text { Symptom } \\
\text { resolution }\end{array}$ & Anaesthesia & Guidance & $\begin{array}{c}\text { No. } \\
\text { sessions }\end{array}$ & Complications & Outcome \\
\hline 1 & $64 \times 33 \times 23$ & $41 \times 22 \times 11$ & $-79.6 \%$ & Complete & L & US & 2 & No & Moderate \\
\hline 2 & $53 \times 43 \times 15$ & $41 \times 30 \times 11$ & $-60.4 \%$ & Complete & $\mathrm{L}$ & US & 2 & Swelling & Moderate \\
\hline 3 & $15 \times 34 \times 38$ & $11 \times 24 \times 26$ & $-64.6 \%$ & Partial & $\mathrm{L}$ & US & 2 & Pain & Moderate \\
\hline 4 & $45 \times 31 \times 20$ & $22 \times 11 \times 10$ & $-91.3 \%$ & Complete & $\mathrm{L}$ & US & 1 & No & Excellent \\
\hline 5 & $50 \times 33 \times 36$ & $26 \times 14 \times 16$ & $-90.2 \%$ & Complete & $\mathrm{L}$ & US & 1 & No & Excellent \\
\hline 6 & $43 \times 37 \times 26$ & $36 \times 28 \times 20$ & $-51.3 \%$ & Partial & $\mathrm{L}$ & US & 2 & No & Moderate \\
\hline 7 & $47 \times 40 \times 30$ & $39 \times 32 \times 26$ & $-42.5 \%$ & None & $G$ & Endoscopy & 2 & No & Poor \\
\hline 8 & $100 \times 32 \times 27$ & $84 \times 23 \times 21$ & $-53 \%$ & Partial & $G$ & Endoscopy & 2 & Swelling & Moderate \\
\hline 9 & $12 \times 11 \times 14$ & $8 \times 5 \times 4$ & $-91.3 \%$ & Complete & $\mathrm{L}$ & Endoscopy & 1 & No & Excellent \\
\hline 10 & $42 \times 30 \times 30$ & $32 \times 24 \times 23$ & $-53.3 \%$ & Partial & G & Endoscopy & 2 & Pain & Moderate \\
\hline 11 & $11 \times 24 \times 20$ & $5 \times 11 \times 9$ & $-90.6 \%$ & Complete & $\mathrm{L}$ & Transoral/US & 1 & No & Excellent \\
\hline 12 & $35 \times 31 \times 43$ & $26 \times 24 \times 26$ & $-65.2 \%$ & Partial & L & US & 1 & No & Moderate \\
\hline 13 & $37 \times 33 \times 30$ & $29 \times 24 \times 18$ & $-65.8 \%$ & Partial & G & US & 1 & Swelling & Moderate \\
\hline 14 & $30 \times 16 \times 12$ & $12 \times 7 \times 6$ & $-91.3 \%$ & Complete & G & Transoral/US & 1 & No & Excellent \\
\hline 15 & $76 \times 40 \times 74$ & $34 \times 20 \times 32$ & $-90.3 \%$ & Complete & $\mathrm{L}$ & US & 1 & No & Excellent \\
\hline 16 & $140 \times 100 \times 60$ & $94 \times 75 \times 48$ & $-59.7 \%$ & Partial & G & Transoral/US & 2 & Pain & Moderate \\
\hline 17 & $16 \times 7 \times 5$ & $12 \times 4 \times 2$ & $-82.9 \%$ & Complete & $\mathrm{L}$ & US & 1 & No & Moderate \\
\hline 18 & $28 \times 16 \times 15$ & $12 \times 9 \times 6$ & $-90.4 \%$ & Complete & $\mathrm{L}$ & Transoral/US & 1 & No & Excellent \\
\hline 19 & $51 \times 47 \times 80$ & $39 \times 26 \times 37$ & $-80.5 \%$ & Complete & $\mathrm{L}$ & US & 1 & No & Moderate \\
\hline 20 & $41 \times 32 \times 33$ & $31 \times 22 \times 17$ & $-73.2 \%$ & Complete & $\mathrm{L}$ & US & 1 & No & Moderate \\
\hline
\end{tabular}

L: local anaesthesia; G: general anaesthesia; dCC: cranio-caudal diameter; LL (latero-lateral); AP (antero-posterior) dCCXLLxAP are expressed in millimetres; US: ultrasound. 
nical details of the procedures. In terms of effectiveness, we observed an excellent response in 9/20 (45\%) patients, a moderate response in $10 / 20(50 \%)$ and poor response in only 1 patient (5\%). Figures 1, 2 and 3 show, respectively, a case of excellent response of a macrocystic LM of the floor of the mouth/submandibular region, a case of moderate response of rhino-oropharyngeal VM and a case of poor response of oro-hypopharyngeal microcystic LM.

According to the type of malformation, we observed the following responses: in macrocystic LMs an excellent response in $4 / 7(57.1 \%)$ and a moderate one in 3/7 (42.9\%); in mixed LMs, a moderate response in all cases (5/5); in the single treated microcystic LM, a poor response; in VMs, an excellent response in $3 / 7(42.9 \%)$ and a moderate one in $4 / 7(57.1 \%)$. Figures 4 and 5 show two cases of excellent response of the oral vestibule VM and tongue VM, respectively.

All patients who obtained an excellent response (7/20) achieved the result after a single session. In the remain- ing 13/20 (65\%) patients, a second treatment was proposed, even if $5 / 13(38.4 \%)$ patients refused because of clinical symptomatic improvement. Finally, 8/13 (61.6\%) patients underwent a second injection and 7/13 (53.8\%) obtained a moderate response and $1 / 13(7.7 \%)$ patients had a poor one at 6-month follow-up.

At long-term follow-up, we did not observe relapse or regrowth of treated lesions confirming that our results were stable over time. Regarding the safety of polidocanol sclerotherapy, no complications were noted during any treatment session. One patient developed a significant pharyngeal swelling after the first injection that resolved in 2-3 days with oral steroids, two patients complained of a significant swelling of the parotid region after intra-lesional injection that resolved in 2-3 days with oral steroids and two patients referred moderate-severe pain after the procedure that resolved in one day with paracetamol. All other patients experienced only mild pain or mild oedema immediately after the procedure. No other complications such

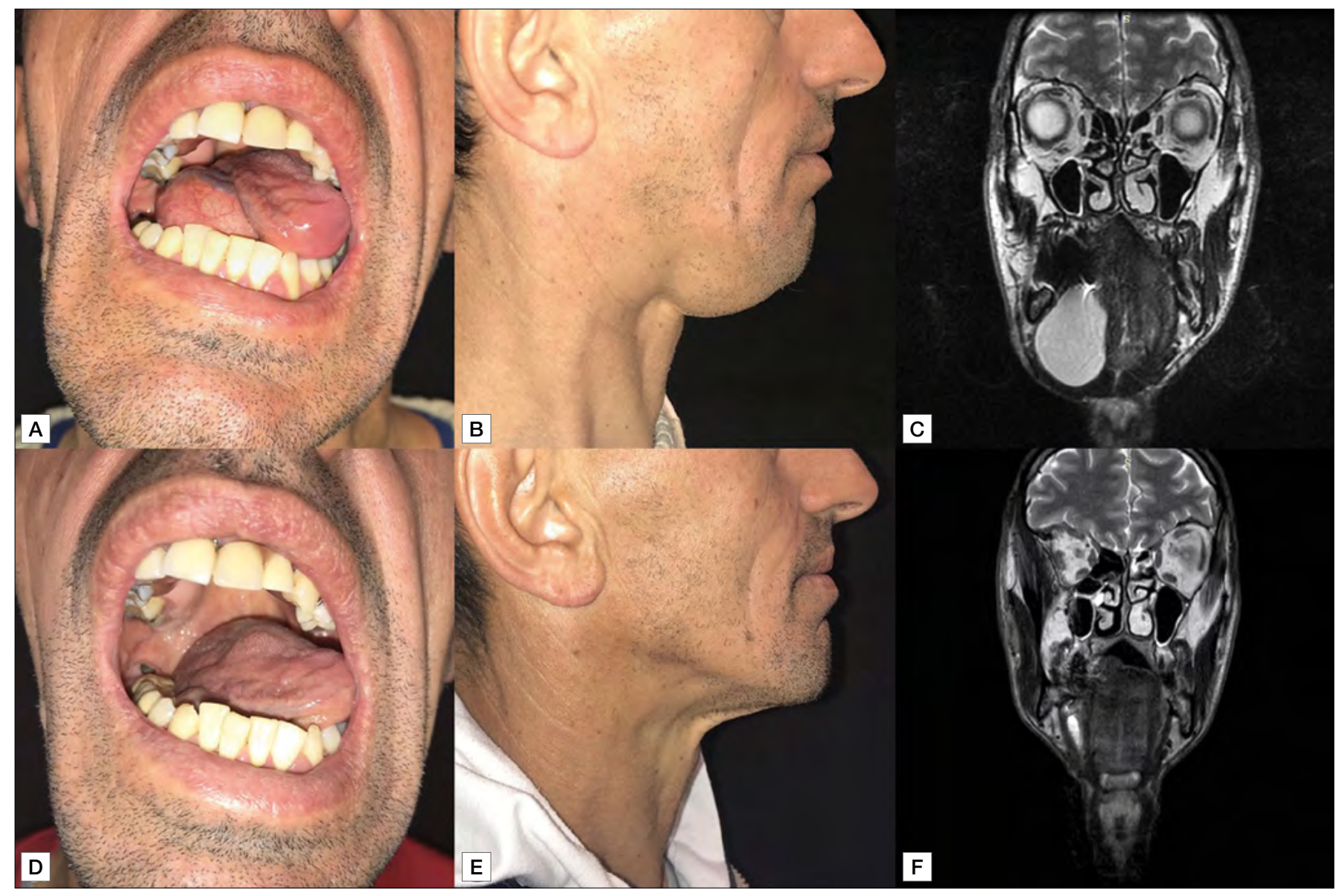

Figure 1. Case 5 (Tabs. II-III): patient with macrocystic-LM of the floor of the mouth and submandibular region which achieved excellent response after one session of 3\% POL sclerotherapy. (A, B): pre-treatment images; (D, E): post-treatment images; (C, F): pre-treatment and 6-months follow up MRI respectively. The LM volume decreased from $30.8 \mathrm{~mL}$ to $3.0 \mathrm{~mL}$. 

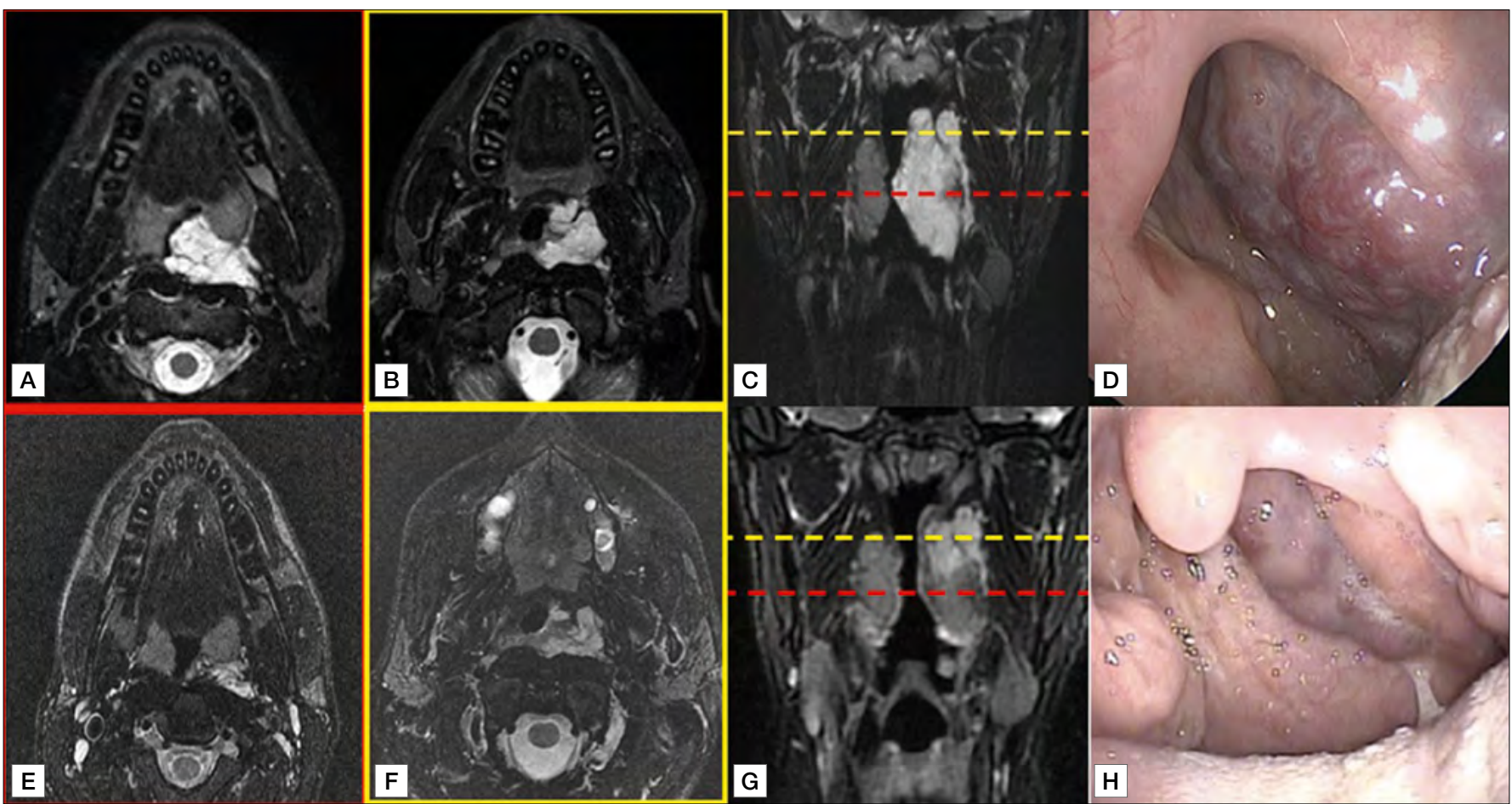

Figure 2. Case 8 (Tabs. II-III): patient with VM of the pharynx which achieved moderate response after two sessions of 3\% POL sclerotherapy. Upper row: pretreatment MRI study and endoscopic view; Lower row: post-treatment MRI study (at 6 months follow up) and endoscopic view. (A, E): axial T2 fat saturated images through the oropharynx; (B, F): axial T2 fat saturated images through the lower portion of nasopharynx; $(\mathbf{C}, \mathbf{G})$ : coronal T2 fat saturated images (red dotted line: the level of the axial images through the oropharynx, yellow dotted line: the level of the axial images through the nasopharynx); (D, H): pre and post-treatment endoscopic views, respectively. The VM volume decreased from $44.9 \mathrm{~mL}$ to $21.1 \mathrm{~mL}$.
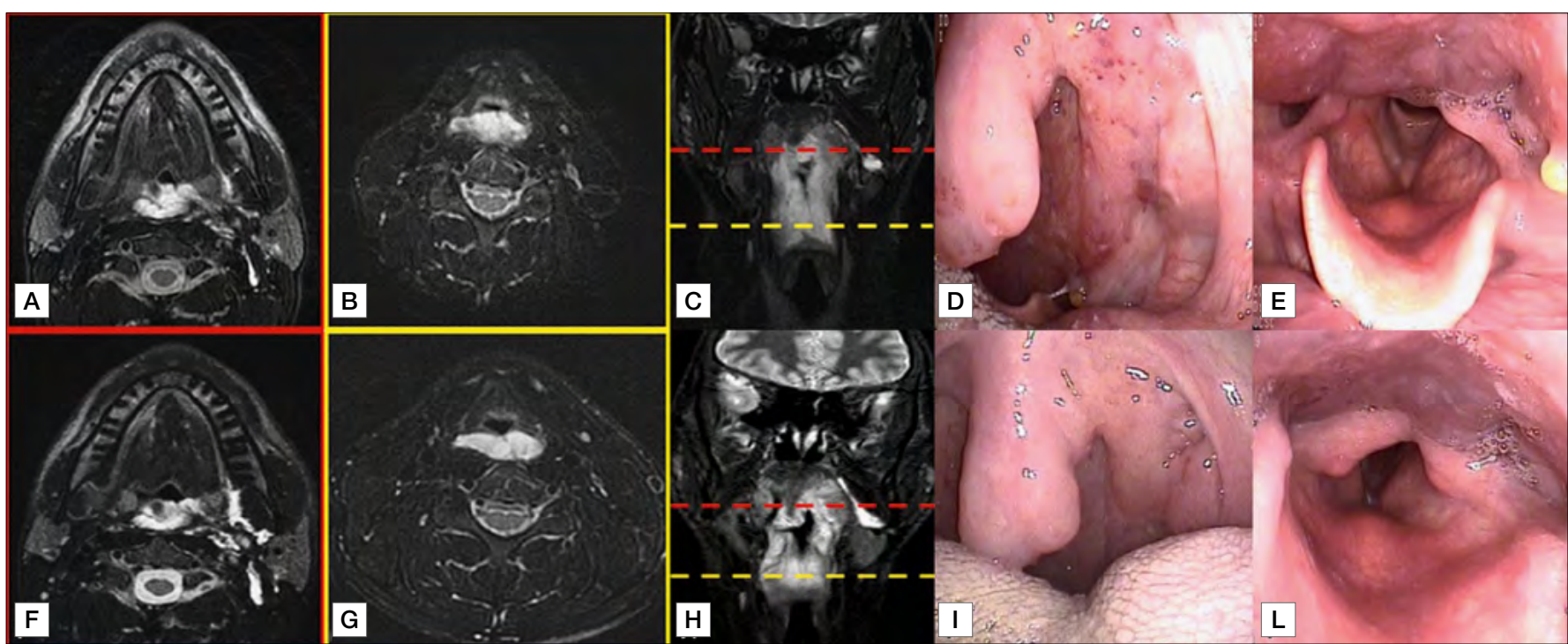

Figure 3. Case 7 (Tabs. II-III): patient with microcystic-LM of the oro-hypopharynx which achieved poor response after two sessions of 3\% POL sclerotherapy. Upper row: pre-treatment MRI study and endoscopic view. Lower row: post-treatment MRI study (at 6 months follow up) and endoscopic view. (A, F): axial T2 fat saturated images through the oropharynx; $(\mathbf{B}, \mathbf{G})$ : axial T2 fat saturated images through the hypopharynx; $(\mathbf{C}, \mathbf{H})$ : coronal T2 fat saturated images (red dotted line: the level of the axial images through the oropharynx; yellow dotted line: the level of the axial images through the hypopharynx); (D, I): pre-treatment and posttreatment endoscopic views of oropharynx, respectively; $(\mathbf{E}, \mathbf{J})$ : pre-treatment and post-treatment endoscopic view of hypopharynx, respectively. The LM volume decreased from $29.3 \mathrm{~mL}$ to $16.8 \mathrm{~mL}$ 


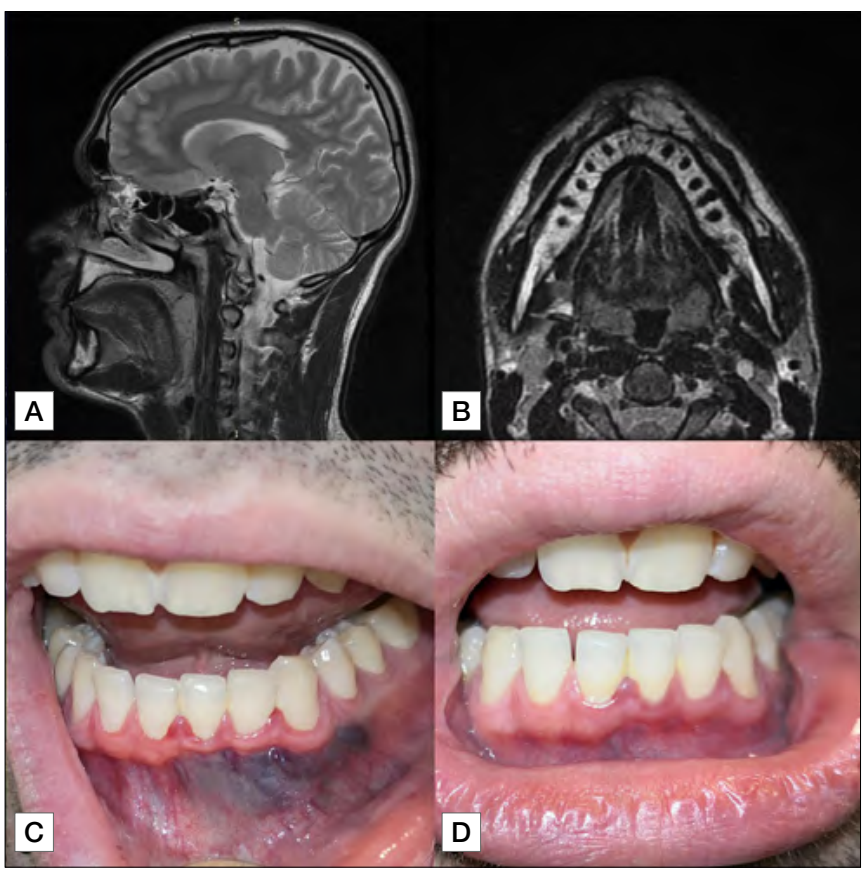

Figure 4. Case 11 (Tabs. II-III): patient with with VM of the oral vestible which achieved excellent response after one sessions of 3\% POL sclerotherapy. (A, B): pre-treatment sagittal and axial T2 fat saturated images; (C): pre-treatment VM of the oral vestibule; (D): 6-month post treatment follow-up. The VM volume decreased from $2.7 \mathrm{~mL}$ to $0.2 \mathrm{~mL}$.

as intra-lesional bleeding, fever, secondary infections, or neurological deficits were observed.

Moreover, we never observed obstruction of upper aerodigestive airways after sclerotherapy.

\section{Discussion}

At present, there are no guidelines for the treatment of head and neck vascular malformations. Surgery remains the gold standard in most cases, although it is burdened by poor aesthetic and functional results. Nowadays, sclerotherapy has become a first-choice treatment, especially in low-flow vascular malformations (venous and lymphatic ones), because it is moderately invasive, well tolerated and effective.

Numerous sclerosing agents have been proposed over the years. Recently, microfoam injection has become increasingly popular thanks to its unique properties and ease of management. In particular, POL is a non-ionic surfactant sclerosing agent that can reduce the volume of malformation by directly damaging the vascular endothelial cells thanks to activation of cellular calcium signalling and nitric oxide pathways. The POL foam displaces blood instead of diluting in it, allowing strict control of the concentration of the agent in the vessel and leading to homogeneous distribution within the lumen. Ultrasound-guided microfoam
POL sclerotherapy has been reported to be safe and effective for treatment of VMs ${ }^{15}$. In a recent manuscript, Hou et al. ${ }^{16}$ described their experience of POL sclerotherapy in 47 patients with VMs and reported a poor outcome for only 2/47 patients. POL sclerotherapy of LMs has been reported in only a few series and rarely in head neck lesions ${ }^{14,17,24}$. Yamaki et al. ${ }^{17}$ described a series of 32 LMs treated with polidocanol sclerotherapy. In that series, only $47 \%$ of cases had a head and neck localisation. The authors observed excellent and moderate responses in $88 \%$ of patients and concluded that polidocanol sclerotherapy should be considered in the treatment of LMs, particularly those that are exclusively macrocystic.

Jain et al. ${ }^{13}$ reported a heterogenous series of vascular malformations treated with $1 \%$ polidocanol and observed an $80 \%$ or greater decrease in the volume of the lesion in the majority of patients; however, they did not further classify lymphangiomas based on dimension of the cysts. Blaise et al. ${ }^{18}$ described a series of 24 cases of low-flow vascular malformations treated with polidocanol (only 9 were located in the head and neck region), reporting $>50 \%$ reduction in $37.5 \%$ of cases and $<50 \%$ reduction in $58.3 \%$ of cases. All studies have confirmed the excellent safety of POL sclerotherapy even if there is some disagreement in terms of effectiveness. This discrepancy is justified by the rarity and significant heterogeneity of vascular malformation in terms of the location, type and dimension. In this series, we describe a series of exclusively head and neck vascular malformations, including upper airway lesions, demonstrating that POL sclerotherapy is an effective and safe procedure both for VMs and LMs. In fact, at 6 months follow-up we observed a mean MRI volume reduction of $73.38 \%$ in the entire series. We observed an excellent response in one single injection in $35 \%$ of patients, and a moderate response in $60 \%$ of patients with one or two injections. Overall, an excellent-moderate response was observed in $95 \%$ of cases. The number of treatment sessions required using POL in our series is comparable to that of other agents ${ }^{7}$. Regarding morbidity of the procedure, we observed only mild side effects that were easy to manage in the early post-operative period. Finally, at long-term followup, we observed that our results were stable over time. We believe that one factor contributing to the high success rate is our radiologist-ENT multidisciplinary approach that is extremely beneficial in the management of these patients in both the pre-treatment setting to characterise the lesion and during the procedure to maximise outcomes. Cooperation is particularly important in the pre-treatment setting in order to identify the best candidate for sclerotherapy, and the optimal time to proceed. Decision to treat in fact is based not only on functional and aesthetic concerns, but also on radiologically documented increases in dimensional lesion. 


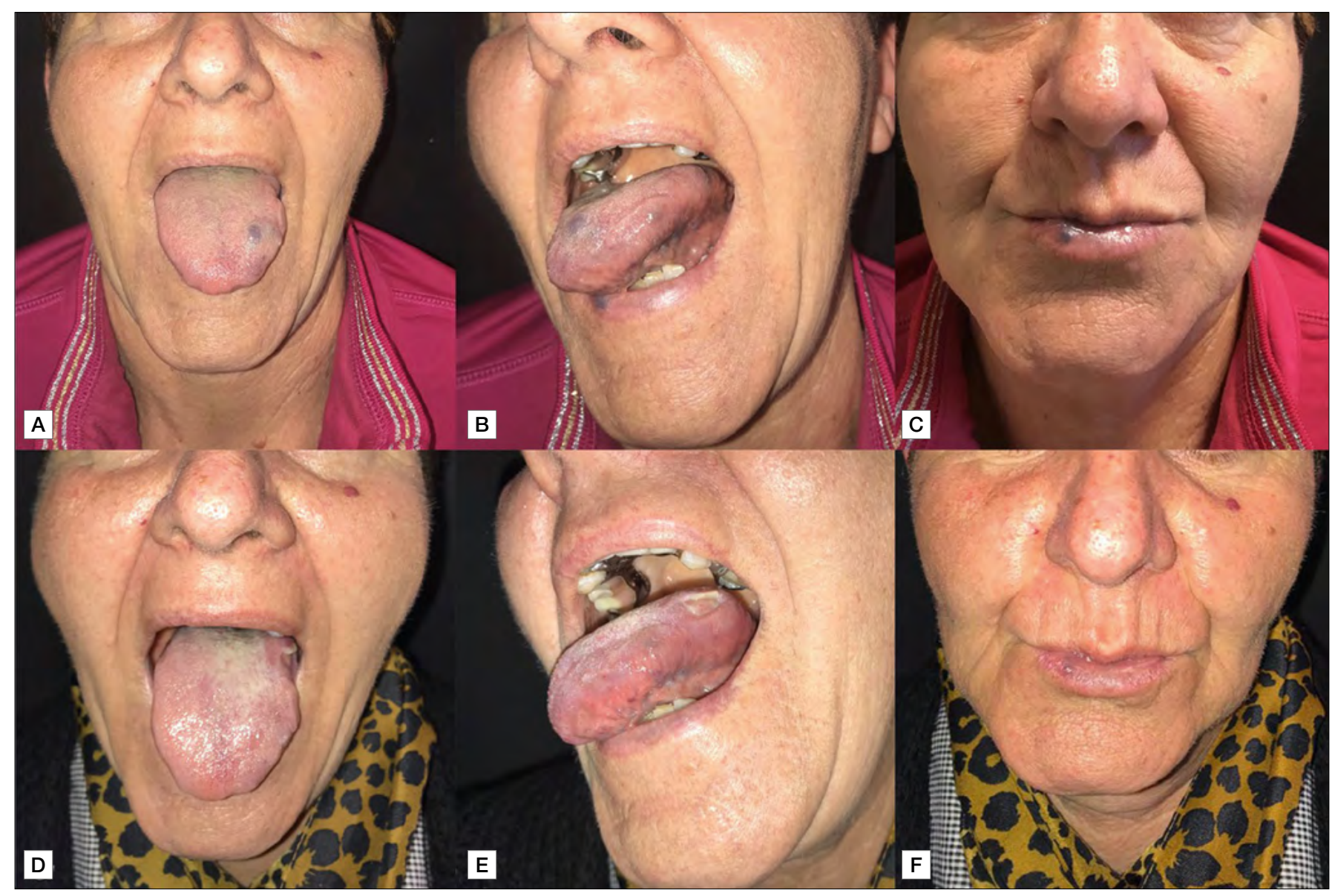

Figure 5. Case 18 (Tabs. III-IV): patient with VM of the tongue which achieved excellent response after one sessions of 3\%POL sclerotherapy. Upper row: pretreatment images; Lower row: post-treatment images. The VM lesion decreased from $2.9 \mathrm{~mL}$ to $0.2 \mathrm{~mL}$. In the same patient we also treated a little VM of the inferior lip with good result.

This study should be interpreted in the context of its strengths and limitations. The strength of our study lies in the homogeneity of treatment strategy: in fact, it is a single-centre study, thus ensuring homogeneity in technique and patient care. All patients received the same procedure, and all patients were required to undergo MRI before treatment and at 6 months after the last injection. None of the lesions had been previously treated and all lesions were localised in the head and neck region. To best of our knowledge, this is one of the larger case series of low flow vascular malformations of head and neck treated with POL foam sclerotherapy. We also performed a subanalysis for type of malformation, observing better responses in head and neck macrocystic LMs and VMs. Furthermore, in agreement with literature data, we observed a moderate response in all mixed LMs and a poor response in microcystic LMs. Finally, we confirmed the safety and effectiveness of the endoscopic-guided intralesional injection of sclerosing agent for treatment of upper airway malformations, firstly described in a small case series ${ }^{25}$. The limits of this study are related to its retrospective design and the lack of standardised method for evaluation of symptoms.

\section{Conclusions}

Our data suggest that polidocanol sclerotherapy, performed in cooperation with a radiologist and otolaryngologist, is an effective and safe procedure in cases of head and neck venous malformations and macrocystic lymphatic ones, and provided very good results in mixed lymphatic malformations as well. These promising results should be confirmed by further and larger prospective studies in order to establish the best indications for this agent.

\section{Conflict of interest statement}

The authors declare no conflict of interest.

\section{Funding}

This research did not receive any specific grant from fund- 
ing agencies in the public, commercial, or not-for-profit sectors.

\section{Authors' contributions}

Conceptualization: EDC; methodology: GS and GDC; validation: EDC; formal analysis: AC, SG and MP; investigation: SG, MP, AC, GS and GDC; data curation: EDC and GDC; writing - original draft preparation: EDC and GDC; writing -review and editing: EDC and GDC; supervision: $\mathrm{CC}$ and GP; project administration: EDC and GDC. All authors have read and agreed to the published version of the manuscript.

\section{Ethical consideration}

This study was approved by the Institutional Ethics Committee (Fondazione Policlinico Universitario Agostino Gemelli IRCCS) [Approval Number/Protocol Number 11142/20 (ID3035)].

The research was conducted ethically, with all study procedures being performed in accordance with the requirements of the World Medical Association's Declaration of Helsinki.

Written informed consent was obtained from each participant/patient for study participation and data publication.

\section{References}

1 Wassef M, Blei F, Adams D, et al. Vascular anomalies classification: recommendations from the International Society for the Study of Vascular Anomalies. Pediatrics 2015;136:e203-214. https://doi. org/10.1542/peds.2014-3673

2 Classification International Society for the Study of Vascular Anomalies. https://www.issva.org/classification. Accessed November 27, 2019.

3 Nosher JL, Murillo PG, Liszewski M, et al. Vascular anomalies: a pictorial review of nomenclature, diagnosis and treatment. World $\mathrm{J}$ Radiol 2014;6:677-692. https://doi.org/10.4329/wjr.v6.i9.677

4 Tasnádi G. Epidemiology and etiology of congenital vascular malformations. Semin Vasc Surg 1993;6:200-203.

5 Ballah D, Cahill AM, Fontalvo L, et al. Vascular anomalies: what they are, how to diagnose them, and how to treat them. Curr Probl Diagn Radiol 2011;40:233-247. https://doi.org/10.1067/j.cpradiol.2011.04.001

6 Espinel AG, Bauman NM. Psychosocial impact of vascular anomalies on children and their families. Otolaryngol Clin North Am 2018;51:99-110. https://doi.org/10.1016/j.otc.2017.09.018

7 Horbach SER, Lokhorst MM, Saeed P, et al. Sclerotherapy for lowflow vascular malformations of the head and neck: a systematic review of sclerosing agents. J Plast Reconstr Aesthetic Surg 2016;69:295304. https://doi.org/10.1016/j.bjps.2015.10.045

8 De Maria L, De Sanctis P, Balakrishnan K, et al. Sclerotherapy for venous malformations of head and neck: systematic review and metaanalysis. Neurointervention 2020;15:4-17. https://doi.org/10.5469/ neuroint.2019.00213

9 Ierardi AM, Colletti G, Biondetti P, et al. Percutaneous sclerotherapy with gelified ethanol of low-flow vascular malformations of the head and neck region: preliminary results. Diagn Interv Radiol 2019;25:459-464. https://doi.org/10.5152/dir.2019.18542
10 Greinwald JH, Burke DK, Sato Y, et al. Treatment of lymphangiomas in children: an update of Picibanil (OK-432) sclerotherapy. Otolaryngol Head Neck Surg 1999;121:381-387. https://doi.org/10.1016/ S0194-5998(99)70225-1

11 Parashar G, Shankar G, Sahadev R, et al. Intralesional sclerotherapy with bleomycin in lymphatic malformation of tongue an institutional experience and outcomes. J Indian Assoc Pediatr Surg 2020;25:80-84. https://doi.org/10.4103/jiaps.JIAPS_2_19

12 Cheng J. Doxycycline sclerotherapy in children with head and neck lymphatic malformations. J Pediatr Surg 2015;50:2143-2146. https:// doi.org/10.1016/j.jpedsurg.2015.08.051

13 Jain R, Bandhu S, Sawhney S, et al. Sonographically guided percutaneous sclerosis using $1 \%$ polidocanol in the treatment of vascular malformations. J Clin Ultrasound 2002;30:416-423. https://doi. org/10.1002/jcu.10091

14 Wang L, Liu F, Huang S. Percutaneous lauromacrogol foam sclerotherapy for the treatment of acute airway compression caused by lymphatic malformations in infants. Biomed Res Int 2018;2018:3878960. https://doi.org/10.1155/2018/3878960

15 Grieb D, Meila D, Greling B, et al. Craniofacial venous malformations treated by percutaneous sclerotherapy using polidocanol: a single-center experience. Acta Radiol Stockh Swed 2019;60:593-601. https://doi.org/10.1177/0284185118795326

16 Hou F, Chen J, Xia M, et al. Percutaneous sclerotherapy with polidocanol under the guidance of ultrasound for venous malformations in children - A retrospective cohort study from a single tertiary medical center. Medicine (Baltimore) 2020;99:e18839. https://doi. org/10.1097/MD.0000000000018839

17 Yamaki T, Sasaki Y, Hasegawa Y, et al. Percutaneous ultrasoundguided sclerotherapy with polidocanol microfoam for lymphatic malformations. J Vasc Surg Venous Lymphat Disord 2017;5:707-714. https://doi.org/10.1016/j.jvsv.2017.03.017

18 Blaise S, Charavin-Cocuzza M, Riom H, et al. Treatment of low-flow vascular malformations by ultrasound-guided sclerotherapy with polidocanol foam: 24 cases and literature review. Eur J Vasc Endovasc Surg 2011;41:412-417. https://doi.org/10.1016/j.ejvs.2010.10.009

19 Warren TA, Gandhi M, Panizza B. Pictorial review: vascular anomalies of the head and neck. J Med Imaging Radiat Oncol 2012;56:8492. https://doi.org/10.1111/j.1754-9485.2012.02342.x

20 de Serres LM, Sie KC, Richardson MA. Lymphatic malformations of the head and neck. A proposal for staging. Arch Otolaryngol Head Neck Surg 1995;121:577-582. https://doi.org/10.1001/archotol.1995.01890050065012

21 Tessari L, Cavezzi A, Frullini A. Preliminary experience with a new sclerosing foam in the treatment of varicose veins. Dermatol Surg 2001;27:58-60.

22 Knegjens JL, Hauptmann M, Pameijer FA, et al. Tumor volume as prognostic factor in chemoradiation for advanced head and neck cancer. Head Neck 2011;33:375-382. https://doi.org/10.1002/hed.21459

23 Lodder WL, Gilhuijs KGA, Lange CAH, et al. Semi-automated primary tumor volume measurements by dynamic contrast-enhanced MRI in patients with head and neck cancer. Head Neck 2013;35:521526. https://doi.org/10.1002/hed.22988

24 Markovic JN, Nag U, Shortell CK. Safety and efficacy of foam sclerotherapy for treatment of low-flow vascular malformations in children. J Vasc Surg Venous Lymphat Disord 2020;8:1074-1082. https://doi. org/10.1016/j.jvsv.2019.11.023

25 Oomen KP, Paramasivam S, Waner M, et al. Endoscopic transmucosal direct puncture sclerotherapy for management of airway vascular malformations. Laryngoscope 2016;126:205-211. https://doi. org/10.1002/lary.25284 